\title{
EDITORIAL SECTION
}

\section{Introduction: \\ Background and Objectives of the World Clean Energy Conference}

$\mathrm{T}$ he Second World Climate Conference took place here in this same hall just one year ago under the auspices of the United Nations. The conclusions of the Intergovernmental Panel on Climate Change (IPCC), which were presented there, seemed clear to environmentalists and climatologists: The Earth's atmosphere is undergoing dramatic changes due to energy-intensive human activities. The frightening aspect of the measurable, scientifically proven anomalies are the exponentially-rising mean values of atmospheric $\mathrm{CO}_{2}$ and $\mathrm{CH}_{4}$. These pollutants are the main causes of global warming, accompanied by rising sea-levels, regional climate-shifts, accelerated desertification, and widespread deterioration of The Biosphere.

Little has been done so far to remedy the causes of these problems in the real world: Emissions are increasing due to unabated consumption and population growth accompanied by drives for modernization, which together are pushing consumption of polluting energies further upwards. Many responsible citizens sincerely hope that in June 1992, the UNCED 'Earth Summit' in Rio will produce the answers on how Humankind can get to grips with the sources of this Man-made threat, which may ultimately put the survival of life on this planet at peril. Effective remedial action will be the urgent priority and great imperative.

The overdue awareness of the shortcomings of the overexploitation of non-renewable resources by humans has been constantly growing through the two decades since the alerting MIT report 'Limits to Growth' was published. But awareness is not enough. Corrections leading to environmental recovery are urgently needed by internationally-applied rules of behaviour in a new world order, where the wasteful madness of wars must belong to the past and a global sense of responsibility and respect will be developed towards The Biosphere of our planet - our only home and life-support.

Accordingly the main objectives of this Conference are:

1) to discuss realistic and expeditious implementation measures in terms of better, environmentally compatible energy sources and systems;

2) to foster a world consensus and due cooperation among the energy players of today to become responsible and sustainable energy suppliers of tomorrow, without further delay;

3 ) to appeal to all citizens of this world to make more responsible use of energy by improving energy efficiency and by choosing cleaner, renewable energy sources; and

4) to encourage financial institutions to consider the longer-term environmental risks ahead of short-term profits, and to abstain from financing short-sighted non-sustainable energy projects.

To achieve these ambitious goals, the Global Energy Charter has been conceived by the World Energy Coalition for discussion at this Conference, for further elaboration and then widespread dissemination to governments, private-sector decision-makers, academics, educators, and throughout the United Nations towards and beyond the Rio Earth Summit, with a clear mandate for timely implementation.

The energy-options for a better future will be costly and without easy choices. They must bring The Biosphere back to balance, to assure survival in good health so far as possible of all living creatures, and they must be financeable and economically sustainable; but at the same time they should allow the still-growing world population equitable development opportunities and nourishment in indiscriminate cultural sovereignty. A truly demanding task for Humankind, collective world intelligence and unparalleled financial efforts will be needed to fulfill it, besides the imperative of limiting human population.

Let me appeal to everybody, within and through this Conference, to act and interact seriously towards a Consensus on these goals to help in saving our planet for future generations and cultures.

Gustav R. GRoB, President

Cercle Mondial du Consensus (CMDC)

and International Clean Energy Consortium

Secretary-General of the World Clean Energy Conference

CMDC Central Secretariat

Kellerweg 38

CH-8055 Zürich, Switzerland. 